\title{
Fatores socioeconômicos e de utilização de serviços de saúde bucal relacionados ao uso de álcool em adultos homens
}

\section{Luiz Francisco Guimarães Gilloni, Jaqueline Vilela Bulgareli, Cinthia Regina Molina de Souza, Julia Gaspar Mancilha, Karine Laura Cortellazzi.}

\section{Resumo}

Identificar os padrões relacionados ao uso de álcool em homens adultos e suas associações com variáveis sociodemográficas e de utilização de serviços de saúde bucal torna-se necessária para promover o conhecimento do estado de saúde de uma comunidade e o entendimento de seus hábitos e comportamentos de risco.

\section{Palavras-chave:}

Álcool, Atenção Primária à Saúde,Saúde bucal.

\section{Introdução}

O uso abusivo de álcool resulta em frequentes problemas que afetam não só o usuário, mas também os outros indivíduos ao seu redor, prejudicando assim a comunidade como um todo. Segundo o relatório da Organização Mundial de Saúde (OMS) de 2017, estimase que $25 \%$ dos adultos (aproximadamente 32 milhões pessoas) têm algum tipo de distúrbio relacionado ao álcool. Os indivíduos que são dependentes de álcool apresentam maior risco de desenvolver problemas de saúde devido ao acesso limitado a má alimentação, atendimento odontológico e falta de cuidados de saúde bucal e saúde geral.

O objetivo do presente estudo foi identificar o uso de álcool em adultos homens e verificar sua associação com as variáveis sociodemográficas e de utilização de serviços de saúde bucal.

\section{Resultados e Discussão}

Estudo transversal analítico, com 87 adultos homens na faixa etária de 20 a 59 anos no ano de 2018, cadastrados nas 7 Unidades de Saúde da Família conveniadas com a FOP-Unicamp, no município de Piracicaba-SP.

O padrão de uso de álcool (variável dependente) foi investigado através da aplicação do instrumento Alcohol Use Disorder Identification Test - AUDIT, validado para o português. As variáveis independentes estudadas foram sociodemográficas e de utilização de serviços de saúde bucal. O teste de qui quadrado foi aplicado para testar a associação entre a variável dependente com as independentes no nível de significância de $5 \%$.

Dos 87 participantes, $86,20 \%$ foram classificados na zona I (prevenção primária: abstinente/baixo risco), $11,50 \%$ na Zona II (orientação básica: de risco) e 2,30\% na zona IV (encaminhamento para serviço especializado: possível dependência).

Do total da amostra, $60,92 \%$ tinham ensino médio ou superior; $80,46 \%$ apresentavam renda mensal de até $2.811,00$ reais; $87,36 \%$ tinham casa própria e $63,22 \%$ estavam empregados no momento. Em relação a saúde $63,22 \%$ tinham doenças crônicas e 77,01\% tinham finalizado o tratamento odontológico. Além disso, houve associação significativa entre moradia, religião e tipo de serviço odontológico com o AUDIT.

Tabela 1. Associação entre as variáveis independentes e a variável dependente (Score do AUDIT).

\begin{tabular}{|c|c|c|c|c|c|c|c|}
\hline \multirow[b]{3}{*}{ Variável } & \multirow[b]{3}{*}{ Categoria } & \multicolumn{4}{|c|}{ AUDIT } & \multirow[b]{3}{*}{ Qui-quadrado } & \multirow[b]{3}{*}{ p-valor } \\
\hline & & \multicolumn{2}{|c|}{ Baixo } & \multicolumn{2}{|c|}{ Alto } & & \\
\hline & & $\mathbf{n}$ & $\%$ & $\mathbf{n}$ & $\%$ & & \\
\hline \multirow{2}{*}{ Estado civil } & Casado & 34 & 56,67 & 26 & 43,33 & 0,304 & 0,5812 \\
\hline & Outros & 17 & 62,96 & 10 & 37,04 & & \\
\hline \multirow{2}{*}{ Escolaridade } & Até Ensino fundamental & 20 & 58,82 & 14 & 41,18 & 0,001 & 0,9755 \\
\hline & Ensino médio e superior & 31 & 58,49 & 22 & 41,51 & & \\
\hline \multirow{2}{*}{ Profissão } & Autônomo & 29 & 60,42 & 19 & 39,58 & 0,142 & 0,7059 \\
\hline & Não autônomo & 22 & 56,41 & 17 & 43,59 & & \\
\hline \multirow{2}{*}{ Doença crônica } & Sim & 33 & 60,00 & 22 & 40,00 & 0,117 & 0,7320 \\
\hline & Não & 18 & 56,25 & 14 & 43,75 & & \\
\hline \multirow{2}{*}{ Utilizou o serviço de saúde } & Sim & 44 & 61,11 & 28 & 38,89 & 1,068 & 0,3015 \\
\hline & Não & 07 & 46,67 & 08 & 53,33 & & \\
\hline \multirow{2}{*}{$\begin{array}{l}\text { Número de pessoas na } \\
\text { familia }\end{array}$} & Até 4 pessoas & 43 & 59,72 & 29 & 40,28 & 0,209 & 0,6476 \\
\hline & Acima de 4 & 08 & 53,33 & 07 & 46,67 & & \\
\hline \multirow{2}{*}{ Moradia } & Própria & 41 & 53,95 & 35 & 46,06 & 5,412 & 0,0200 \\
\hline & Não própria & 10 & 90,91 & 01 & 9,09 & & \\
\hline \multirow{2}{*}{ Renda familiar } & $\leq 2811,00$ reais & 44 & 62,86 & 26 & 37,14 & 2,651 & 0,1035 \\
\hline & $>2811,00$ reais & 07 & 41,18 & 10 & 58,82 & & \\
\hline \multirow{2}{*}{ Condição de trabalho } & Empregado & 31 & 56,36 & 24 & 43,64 & 0,314 & 0,5752 \\
\hline & Desempregado/Aposentado & 20 & 62,50 & 12 & 37,50 & & \\
\hline \multirow{2}{*}{ Religião } & Católica & 16 & 44,44 & 20 & 55,56 & 5,088 & 0,0241 \\
\hline & Outras & 35 & 68,63 & 16 & 31,37 & & \\
\hline \multirow{2}{*}{$\begin{array}{l}\text { Tipo de serviço } \\
\text { odontológico }\end{array}$} & Publico & 20 & 47,62 & 22 & 52,38 & 4,052 & 0,0441 \\
\hline & Particular & 31 & 68,89 & 14 & 31,11 & & \\
\hline \multirow{2}{*}{ Última consulta ao dentista } & No último ano & 25 & 55,56 & 20 & 44,44 & 0,361 & 0,5479 \\
\hline & Há mais de um ano & 26 & 61,90 & 16 & 38,10 & & \\
\hline \multirow{2}{*}{$\begin{array}{l}\text { Motivo do tratamento } \\
\text { odontológico }\end{array}$} & Dor/Extração & 27 & 56,25 & 21 & 43,75 & 0,248 & 0,6184 \\
\hline & Outros & 24 & 61,54 & 15 & 38,46 & & \\
\hline \multirow{2}{*}{$\begin{array}{l}\text { Tratamento odontológico } \\
\text { finalizado }\end{array}$} & Sim & 42 & 57,0 & 25 & 43,0 & 1,986 & 0,1587 \\
\hline & Não & 09 & 19,0 & 11 & 81,0 & & \\
\hline
\end{tabular}

\section{Conclusões}

A maioria dos indivíduos $(86,20 \%)$ foram classificados como baixo risco do uso de álcool e os fatores associados com o AUDIT foram moradia, religião e tipo de serviço odontológico. 